\title{
Anti-angiogenic effects of liposomal prednisolone phosphate on B16 melanoma in mice
}

\author{
Manuela Banciu ${ }^{\mathrm{a}, \mathrm{b}}$, Raymond M. Schiffelers ${ }^{\mathrm{a}}$, Marcel H.A.M. Fens ${ }^{\mathrm{a}}$, \\ Josbert M. Metselaar ${ }^{\text {a }}$, Gert Storm ${ }^{\mathrm{a}, *}$ \\ a Department of Pharmaceutics, Utrecht Institute for Pharmaceutical Sciences (UIPS), Utrecht University, Utrecht, The Netherlands \\ b Department of Pharmaceutical Technology and Biopharmaceutics, "Iuliu Hatieganu” University of Medicine and Pharmacy, Cluj-Napoca, Romania
}

Received 17 February 2006; accepted 30 March 2006

Available online 7 April 2006

\begin{abstract}
Prednisolone phosphate (PLP) encapsulated in long-circulating liposomes can inhibit tumor growth after intravenous administration (i.v.). These antitumor effects of liposomal PLP are the result of the tumor-targeting property of the liposome formulation. The mechanism by which liposomal PLP inhibits tumor growth is unclear. We investigated the effects of liposome-encapsulated PLP versus free PLP on angiogenic protein production in tumor tissue in vivo and on viability and proliferation of tumor and endothelial cells in vitro. In vivo, liposomal PLP had a stronger reducing effect on pro-angiogenic protein levels than free PLP, whereas levels of anti-angiogenic proteins were hardly affected. Cell viability was only slightly affected with either treatment. Liposomal PLP had strong anti-proliferative effects on human umbilical vein endothelial cells, whereas free PLP had hardly any effect. Taken together, the present study points to a strong inhibitory effect of liposomal PLP on tumor angiogenesis by reduction of the intratumoral production of the majority of pro-angiogenic factors studied and direct inhibition of endothelial cell proliferation, which is the result of high prolonged levels of prednisolone in the tumor by liposomal delivery.
\end{abstract}

(C) 2006 Elsevier B.V. All rights reserved.

Keywords: Liposomes; Drug targeting; Angiogenesis; Cancer; Glucocorticoids

\section{Introduction}

Our previous studies indicate that PLP encapsulated in longcirculating liposomes exerts strong inhibitory effects on tumor growth in a low dose and low frequency schedule after intravenous administration. Liposomal PLP inhibits tumor growth by 80-90\% in subcutaneous B16.F10 melanoma and C26 colon carcinoma murine tumor models at a dose of $20 \mathrm{mg} / \mathrm{kg}$ [1]. In the case of free (i.e. non-encapsulated) PLP, the antitumor effects have only been observed using treatment schedules based on high and frequent dosing for prolonged periods of time. These

\footnotetext{
* Corresponding author. Room Z721, Department of Pharmaceutics, Utrecht Institute for Pharmaceutical Sciences (UIPS), Utrecht University, PO Box 80082, 3508 TB Utrecht, The Netherlands. Tel.: +31 30 2537388; fax: +31 30 2517839.

E-mail address: g.storm@pharm.uu.nl (G. Storm).
}

doses resulted in a considerable morbidity and mortality as a result of severe immune suppression [1]. Therefore, targeted delivery of glucocorticoids (GC) to tumor tissue is an attractive strategy to increase intratumoral drug concentration and to prolong the antitumor effects of GC. By virtue of the enhanced permeability of tumor vasculature, as compared to healthy endothelium, long-circulating liposomes are able to extravasate into subcutaneous tumor tissue thereby increasing and prolonging intratumoral glucocorticoid (GC) concentrations. The mechanism by which extravasated liposomal PLP inhibits tumor growth is, however, unclear.

It is known that GC can exert a broad variety of activities on mammalian cells including immunosuppressive, anti-inflammatory, apoptotic, necrotic and anti-angiogenic effects. In principle, all these effects, both at the genomic and non-genomic level, could play a role in the antitumor activity exerted by liposomal PLP [1]. The genomic mechanisms can be induced by very low concentrations of GC. These mechanisms are determined by the 
interaction of $\mathrm{GC}$ with their cytosolic receptors (cGCR) followed by cGCR activation and translocation into the nucleus. Once in the nucleus, $\mathrm{GC} / \mathrm{cGCR}$ complexes modulate the activity of transcription factors, such as activator protein-1 (AP-1), nuclear factor $\mathrm{kB}$ (NF-kB) and nuclear factor of activated T cells (NF-AT). This leads to regulation of the expression of genes for many immunoregulatory and inflammatory cytokines (TNF- $\alpha$, GM-CSF, IL-1â, IL-2, IL-3, IL-6, IL-8, IL-11), for apoptotic proteins (members of the Bcl-2 family such as Bcl- $\mathrm{x}_{\mathrm{s}}$, Bad, Bax, $\mathrm{Bid}, \mathrm{FasL}$ ) as well as for pro-angiogenic proteins (like bFGF and VEGF) [2-4]. Higher dosages increase cGCR occupation, which intensifies the GC effects at the genomic level. If cGCR are saturated, GC can additionally induce non-genomic effects. Non-genomic actions comprise three different mechanisms: 1) cGCR-mediated inhibition of arachidonic acid release, 2) intercalation of GC molecules into cellular membranes altering cationic transport through the plasma membrane and increasing proton leak out of the mitochondria, and 3) binding of GC to specific membrane-bound receptors [5]. The responses induced by non-genomic mechanisms of GC include immunosuppressive and anti-inflammatory effects and induction of necrosis.

To gain further insight into the mechanism of action of liposomal GC, we investigated the effects of liposomal PLP and free PLP on angiogenic protein levels in vivo, as well as on tumor cell and endothelial cell viability and proliferation in vitro. PLP encapsulated in long-circulating liposomes induced a strong inhibition of tumor angiogenesis by reduction of the intratumoral production of the majority of pro-angiogenic factors studied and by direct inhibition of endothelial cell proliferation.

\section{Materials and methods}

\subsection{Liposome preparation}

Long-circulating liposomes were prepared as described previously [1]. In brief, appropriate amounts of dipalmitoylphosphatidylcholine (Lipoid GmbH, Ludwigshafen, Germany), cholesterol (Sigma, St. Louis, USA), and poly(ethylene glycol) 2000-distearoylphosphatidylethanolamine (Lipoid $\mathrm{GmbH}$ ) in a molar ratio of 1.85:1.0:0.15, respectively, were dissolved in ethanol in a round-bottom flask. A lipid film was made under reduced pressure on a rotary evaporator and dried under a stream of nitrogen. Liposomes were formed by addition of an aqueous solution of $100 \mathrm{mg} / \mathrm{ml}$ prednisolone phosphate (Bufa, Uitgeest, The Netherlands). A water-soluble phosphate derivative of prednisolone was used to ensure stable encapsulation in the liposomes. Liposome size was reduced by multiple extrusion steps through polycarbonate membranes (Nuclepore, Pleasanton, USA) with a final pore size of $50 \mathrm{~nm}$. Mean particle size of the liposomes was determined by dynamic light scattering and found to be $0.1 \mu \mathrm{m}$ with a polydispersity value lower than 0.1 . The polydispersity values obtained indicate limited variation in particle size. Phospholipid content was determined with a phosphate assay, performed on the organic phase after extraction of liposomal preparations with chloroform, according to Rouser [6]. The aqueous phase after extraction was used for determining the prednisolone phosphate content by high performance liquid chromatography as described previously [7]. The type of column was RP18 $(5 \mu \mathrm{m})$ (Merck, Germany) and the mobile phase consisted of acetonitril and water $(1: 3 \mathrm{v} / \mathrm{v}), \mathrm{pH} 2$. The eluent was monitored with an ultraviolet detector set at $254 \mathrm{~nm}$.

The detection limit for the high performance liquid chromatography setup was $20 \mathrm{ng} / \mathrm{ml}$. The liposomal preparation contained $\sim 5 \mathrm{mg}$ prednisolone phosphate $/ \mathrm{ml}$ and $\sim 70 \mu \mathrm{mol}$ phospholipid $/ \mathrm{ml}$. As control, empty liposomes were prepared with the same lipid composition but without incorporated drug.

\subsection{Cells}

B16.F10 murine melanoma and C26 murine colon carcinoma cells were cultured as monolayers at $37{ }^{\circ} \mathrm{C}$ in a $5 \% \mathrm{CO}_{2}$ containing humidified atmosphere in DMEM medium (Gibco, Breda, The Netherlands) supplemented with $10 \%(\mathrm{v} / \mathrm{v})$ heatinactivated fetal calf serum (Gibco), $100 \mathrm{IU} / \mathrm{ml}$ penicillin, $100 \mu \mathrm{g} /$ $\mathrm{ml}$ streptomycin and $0.25 \mu \mathrm{g} / \mathrm{ml}$ amphotericin B (Gibco). Human

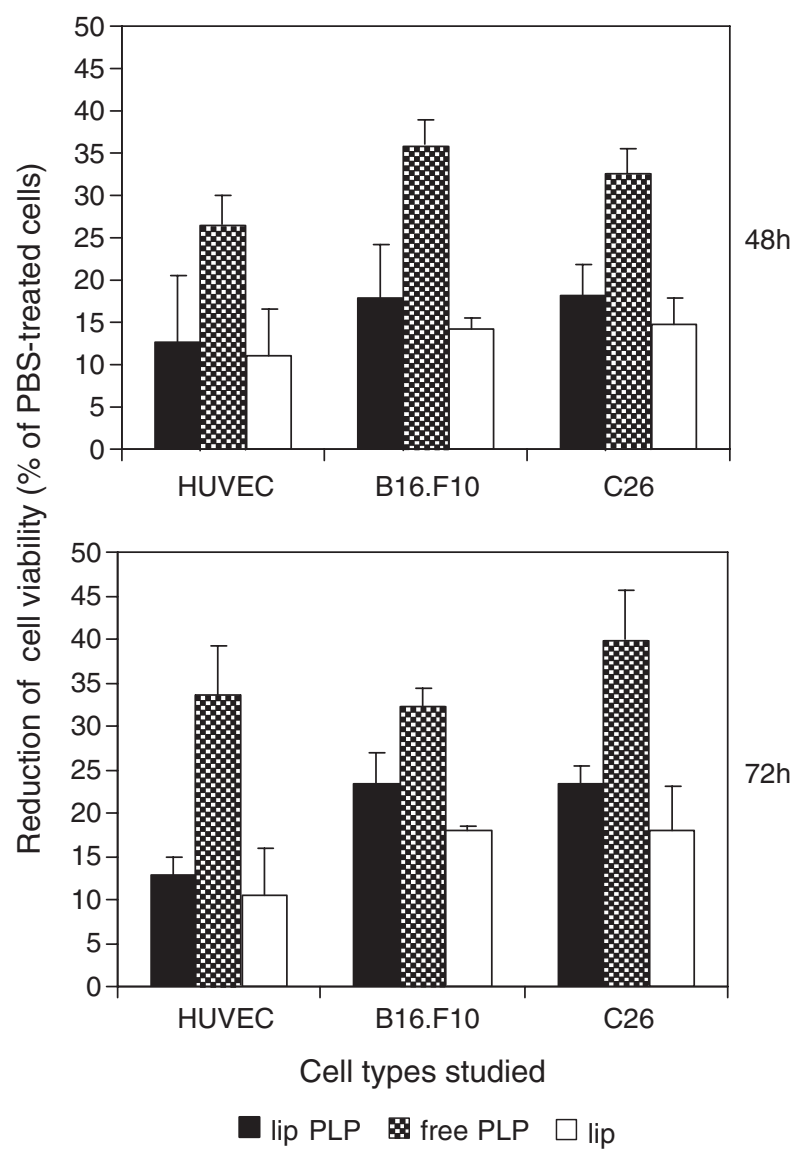

Fig. 1. Effect of liposomal PLP and free PLP on cell viability. HUVEC, B16. $\mathrm{F} 10$, and $\mathrm{C} 26$ cells were incubated for 24,48 , and $72 \mathrm{~h}$ with increasing concentrations of PLP ranging from 5 to $200 \mu \mathrm{g}$ PLP/ml. Cell viability was not reduced for any cell type at any concentration at the earliest time point $(24 \mathrm{~h})$. Also, at 48 and $72 \mathrm{~h}$, lower drug concentrations tested $(5-100 \mu \mathrm{g} / \mathrm{ml})$ did not affect cell viability. Only data obtained at the concentration of $200 \mu \mathrm{g}$ prednisolone phosphate/ml are shown. Mean \pm S.D.; $n=3$ measurements; lip $\mathrm{PLP}=$ liposomal prednisolone phosphate; free PLP $=$ free prednisolone phosphate; lip=empty liposomes. 
umbilical vein endothelial cells (HUVEC) (Glycotech, Rockville, USA) were cultured as a monolayer at $37{ }^{\circ} \mathrm{C}$ in a $5 \% \mathrm{CO}_{2^{-}}$ containing humidified atmosphere in complete EGM endothelial cell growth medium (Cambrex, East Rutherford, NJ, USA).

For in vitro studies, the following protocol was established. Cells were detached from the flasks by trypsinization and counted in a Bürker-counting chamber under the microscope in the presence of trypan blue. Only cells excluding the dye were counted as viable cells. Cells were plated in 96-well plates at the appropriate concentrations according to the assay performed.

\subsection{Murine tumor model}

Male C57B1/6 mice (6-8 weeks of age) were obtained from Charles River (The Netherlands) and kept in standard housing with standard rodent chow and water available ad libitum, and a $12 \mathrm{~h} \mathrm{light/dark} \mathrm{cycle.} \mathrm{Experiments} \mathrm{were} \mathrm{performed} \mathrm{according} \mathrm{to}$ the national regulations and were approved by the local animal experiments ethical committee. For tumor induction, $1 \times 10^{6}$ B16.F10 melanoma cells were inoculated subcutaneously in the flank of syngeneic C57Bl/6 mice. B16.F10 tumors became palpable around 7 days after tumor cell inoculation.

\subsection{Effects of liposomal PLP versus free PLP on cell viability in vitro}

To determine whether liposomal PLP and free PLP (i.e. not encapsulated in liposomes) had a direct cytotoxic effect on cells, $5 \times 10^{3}$ HUVEC, C26 and B16.F10 cells/well were plated in a 96well plate for $24 \mathrm{~h}$. Then, liposomal PLP and free PLP were added in PBS and incubated for $24 \mathrm{~h}, 48 \mathrm{~h}$, and $72 \mathrm{~h}$. After exposure time, cell viability was determined by XTT-assay (Sigma, St. Louis, USA) according to the manufacturer's instructions [8]. All three cell types were incubated with tetrazolium salt XTT and electron-coupling reagent ( $N$-methyl dibenzopyrazine methylsulfate) for $1 \mathrm{~h}$ at $37^{\circ} \mathrm{C}$ in the $\mathrm{CO}_{2}$-incubator. Using an ELISA

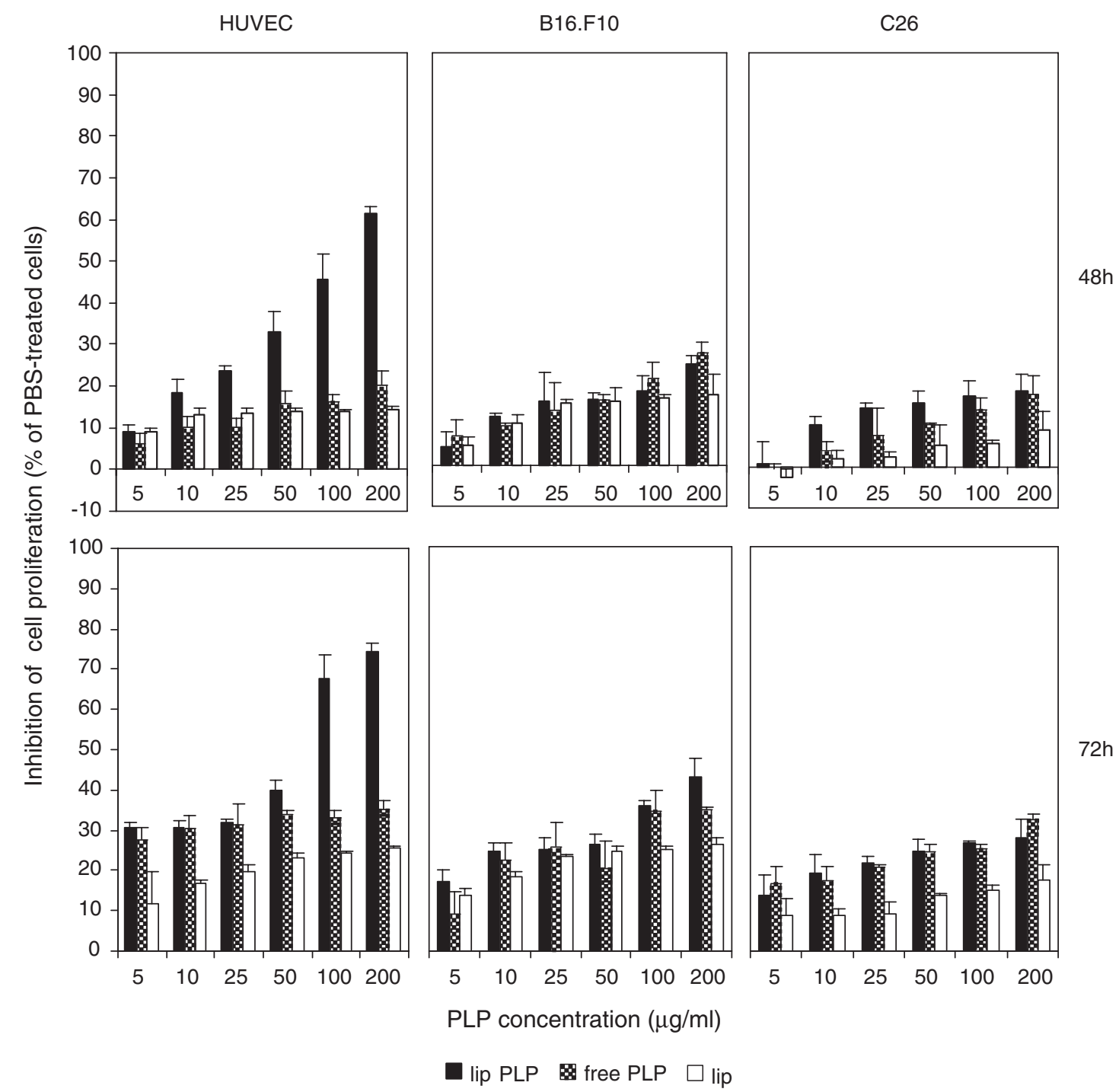

Fig. 2. Effects of liposomal PLP and free PLP on cell proliferation. HUVEC, B16.F10, and C26 cells were incubated for 24,48 and $72 \mathrm{~h}$ with increasing concentrations of PLP ranging from 5 to $200 \mu \mathrm{g} \mathrm{PLP} / \mathrm{ml}$. Cell proliferation was unaffected after $24 \mathrm{~h}$ incubation. Therefore, results are only shown for $48 \mathrm{~h}$ and $72 \mathrm{~h}$ incubation. Mean \pm S.D.; $n=3$ measurements; lip PLP=liposomal prednisolone phosphate; free PLP=free prednisolone phosphate; lip=empty liposomes. 
microplate reader, the absorbance was measured at $490 \mathrm{~nm}$ with a reference wavelength of $655 \mathrm{~nm}$.

\subsection{Effects of liposomal PLP versus free PLP on cell proliferation in vitro}

To determine the effect of PLP (liposomal and free) on cell proliferation, $1 \times 10^{3}$ HUVEC, C26 and B16.F10 cells/well were plated in a 96-well plate for $24 \mathrm{~h}$. Subsequently, liposomal PLP and free PLP, were added in PBS. The anti-proliferative effect of (liposomal and free) PLP was determined after $24 \mathrm{~h}$, $48 \mathrm{~h}$, and $72 \mathrm{~h}$ of incubation by ELISA BrdU-colorimetric immunoassay (Roche Applied Science, Penzberg, Germany) according to the manufacturer's instructions $[9,10]$. This technique is based on the incorporation of the pyridine analogue bromodeoxyuridine (BrdU) instead of thymidine into the DNA of proliferating cells. Cells were incubated with BrdU solution for $24 \mathrm{~h}$ and then media were completely removed from the wells. Then, cells were fixed and DNA was denatured. To detect BrdU incorporated in newly synthesized cellular DNA, a monoclonal antibody conjugated with peroxidase, anti-BrdUPOD, was added. After 90 min of incubation, antibody was removed and cell lysates were washed three times with PBS. The immune complexes were detected by the subsequent substrate of peroxidase (tetramethyl-benzidine) reaction. The reaction product was quantified by measuring the absorbance at $450 \mathrm{~nm}$ with a reference wavelength of $655 \mathrm{~nm}$.

\subsection{Effects of liposomal PLP versus free PLP on the production of angiogenic factors in vivo}

At 7 days after tumor cell inoculation, tumor size was measured and tumor volume calculated according to the formula
$V=0.52 \times a^{2} \times b$, in which $a$ is the smallest and $b$, the largest superficial diameter.

3-4 animals were used per experimental group. The first group was used as control and treated with PBS. The second group was treated with empty liposomes. The third group was treated with free PLP. The fourth group was treated with liposomal PLP. Free PLP and liposomal PLP were administered i.v. at a dose of $20 \mathrm{mg} / \mathrm{kg}$ at days 7, 10 and 13 after tumor cell inoculation. On day 14, the mice were sacrificed and tumors were isolated. Empty liposomes were administered i.v. using the same lipid concentration as for PLP-loaded liposomes.

To evaluate the effect of free PLP and liposomal PLP at a molecular scale, a screening of angiogenic proteins present in tumor tissues was performed using an angiogenic protein array of RayBio ${ }^{\circledR}$ Mouse Angiogenic protein Antibody Array membranes 1.1 (RayBiotech Inc., Norcross, GA) [11]. Each membrane contains 24 types of primary antibodies against certain angiogenic proteins. To detect the levels of angiogenic factors, the tumor tissue for each group was lysed with Cell Lysis Buffer, provided by manufacturer, after $30 \mathrm{~min}$ of incubation. Protease Inhibitor Cocktail (Sigma) was added to the lysis buffer. After obtaining the pooled tumor tissue lysates for each group, the protein content of the lysates was determined by protein determination according to Peterson [12]. One array membrane was used per tumor tissue lysate. The array membrane was incubated with $250 \mu \mathrm{g}$ of protein from tissue lysate for $2 \mathrm{~h}$, at room temperature. Each membrane was incubated with a mixture of secondary Biotin-Conjugated Antibodies against the same angiogenic factors as those for primary antibodies bound onto the membranes, for $2 \mathrm{~h}$, at room temperature. Then, membranes were incubated with HRP-conjugated streptavidin for $2 \mathrm{~h}$, at room temperature. After that, the membranes were incubated with a mixture of two detection buffers, provided by manufacturer, for $1 \mathrm{~min}$, at room temperature.

Table 1

Effects of i.v. administered liposomal PLP and free PLP on pro-angiogenic protein levels in subcutaneous B16.F10 tumor tissue

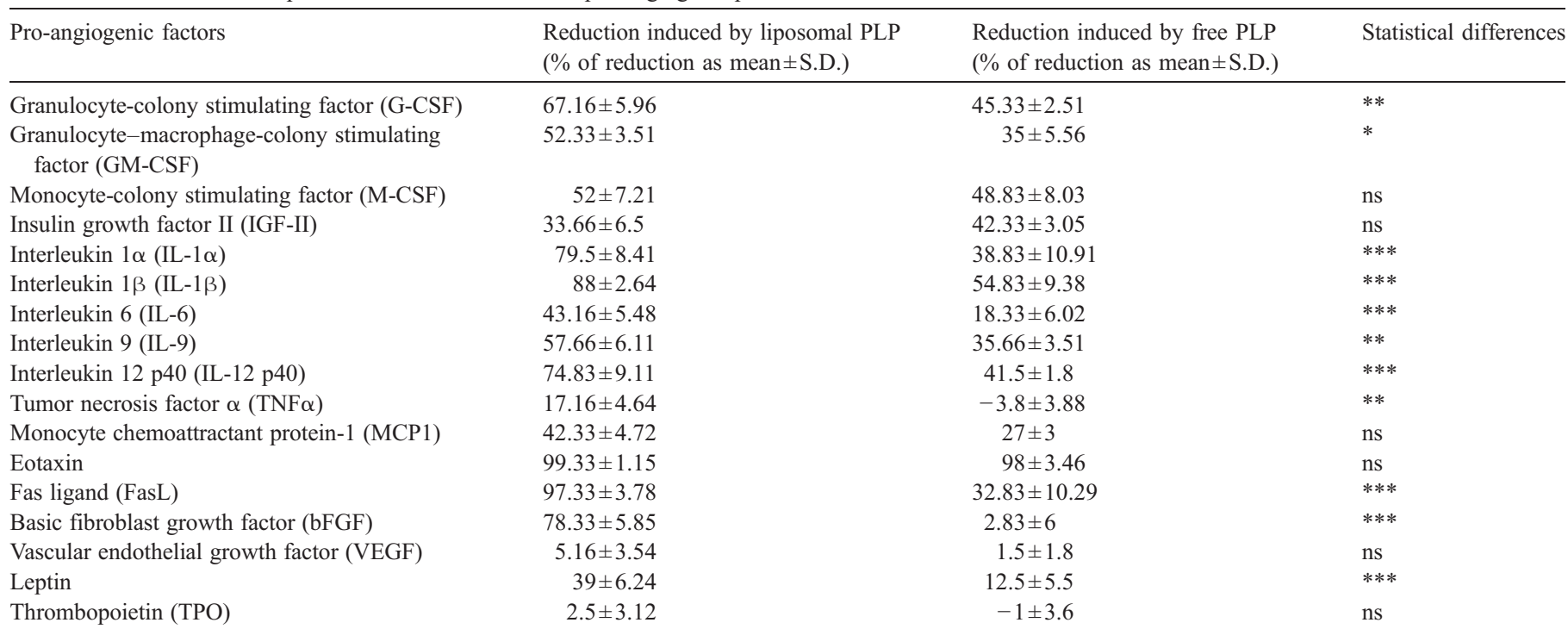

Pro-angiogenic factors are defined as proteins reported in literature to favoring angiogenesis and tumor-associated inflammation. The protein levels are compared to control protein levels in PBS-treated tumors. The results were analyzed for statistically significant differences between the effects of different treatments on the levels of pro-angiogenic factors. A two-way ANOVA with Bonferroni correction for multiple comparisons was used and the $P$ values are indicated as follows: ns, not significant $(P>0.05) ;^{*}, P<0.05 ; * *, P<0.01$; and ${ }^{* *}, P<0.001$. The results represent mean \pm S.D. of three independent experiments. 
Each step of membrane incubation was followed by five washing steps. The membranes were exposed to X-ray film for $4 \mathrm{~min}$ and signal detected using film developer. Each protein for each experimental group was determined in duplicate. The tumor protein levels were obtained by quantification of the color intensity of each spot. Using GelPro Analyzer software, version 3.1, the color intensity was determined for each spot in comparison to positive control spots already bound to the membrane. Then the angiogenic protein levels in tumors treated with empty liposomes, free PLP, and liposomal PLP were expressed as percentage of inhibition by comparison to tumor angiogenic protein levels in tumors treated with PBS. The final results represent mean \pm S.D. of three independent experiments.

\subsection{Statistical analysis}

Data from different experiments were reported as mean $\pm \mathrm{S}$. $D$. For statistical analysis, Student's $t$-test for independent means was used. A value of $P<0.05$ was considered significant. The differences between the effects of different treatments on angiogenic factors were analyzed by two-way ANOVA with Bonferroni correction for multiple comparisons using GraphPad Prism version 4.02 for Windows, GraphPad Software (San Diego, CA).

\section{Results}

\subsection{Effects on cell viability in vitro}

To evaluate the cytotoxic effects of liposomal PLP versus free PLP, HUVEC, B16.F10, and C26 cells were incubated in vitro for 24,48 , and $72 \mathrm{~h}$ with increasing concentrations ranging from 5 to $200 \mu \mathrm{g} / \mathrm{ml}$. The same cell types incubated with PBS were used as control. The differences in viability of cells incubated with PBS and cells incubated with culture media were not significant. Cell viability was not reduced for any cell type at any concentration at the earliest time point ( $24 \mathrm{~h})$. Also, at 48 and $72 \mathrm{~h}$, lower drug concentrations tested $(5-100 \mu \mathrm{g} / \mathrm{ml}) \mathrm{did}$ not affect cell viability. Therefore, Fig. 1 presents only the relative cytotoxic effects of liposomal PLP and free PLP for the highest concentration tested $(200 \mu \mathrm{g} / \mathrm{ml})$ at 48 and $72 \mathrm{~h}$.

For all cell types tested, the viability reduction induced by free drug (ranging from $25 \%$ to $45 \%$ ) was higher as compared to the liposomal drug reduction (ranging from $10 \%$ to $25 \%$ ). The minor cytotoxic effects induced by liposomal PLP are probably due to liposomal lipids rather than the encapsulated drug, as empty liposomes (i.e. devoid of drug) induced the same degree of viability reduction.

\subsection{Effects on cell proliferation in vitro}

To study the anti-proliferative effects of liposomal PLP versus free PLP, HUVEC, B16.F10, and C26 cells were incubated in vitro for 24,48 and $72 \mathrm{~h}$ with increasing concentrations of PLP ranging from 5 to $200 \mu \mathrm{g} / \mathrm{ml}$. Results are shown in Fig. 2.
Inhibition of cell proliferation was moderate (up to 35\%) for all three cell types incubated with free PLP. Slightly stronger inhibitory effects were observed when the B16.F10 and C26 tumor cells are incubated with liposomal PLP. This effect is due to the liposomal lipids rather than the encapsulated drug, as empty liposomes (i.e. devoid of drug) induced a similar degree of proliferation inhibition.

Remarkably, only in case of the HUVEC, liposomal PLP yielded a strong inhibitory effect on cell proliferation (up to $75 \%$ at the highest concentration tested after $72 \mathrm{~h}$ of incubation) which was clearly mediated by the encapsulated PLP.

\subsection{Effects on production of angiogenic factors in vivo}

To study the effects of liposomal PLP and free PLP on levels of angiogenic proteins in tumor tissue, we used the subcutaneous B16.F10 murine melanoma model. In accordance with our previous data [1], growth of tumors treated by liposomal PLP was inhibited by $85 \%$ compared to controls, whereas free PLP did not affect tumor growth. A screening of angiogenic proteins present in tumor tissue was performed using an angiogenic protein array. With this array, levels of 24 proteins involved in angiogenesis, inflammation and apoptosis can be determined. The differences in protein levels in tumors treated with PBS and those in tumor treated with empty liposomes were not statistically significant

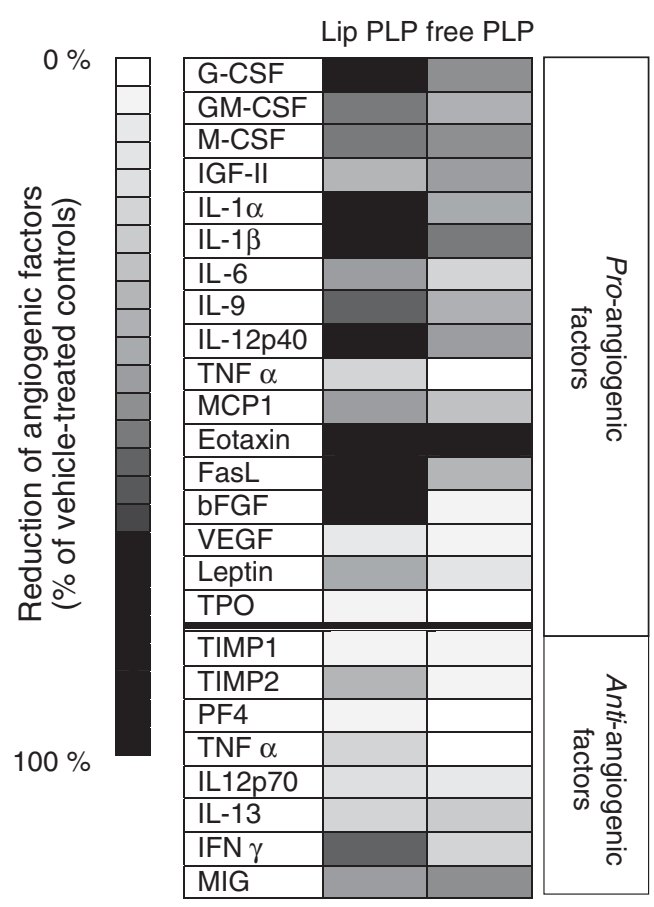

Fig. 3. Effects of liposomal PLP and free PLP on levels of angiogenic factors in vivo. Free PLP and liposomal PLP were administered i.v. at a dose of $20 \mathrm{mg} / \mathrm{kg}$ at days 7, 10 and 13 after tumor cell inoculation. Only liposomal PLP reduced tumor growth over $85 \%$, whereas free PLP did not affect tumor growth rate. On day 14 , the mice were sacrificed and tumors were isolated. Tumors were lysed and levels of angiogenic proteins in the lysates were analyzed by an angiogenic protein array. Degree of reduction of levels of tumor angiogenic factors ranged from $0 \%$ (white) to $100 \%$ (black) compared to angiogenic factors in vehicle treated controls; lip PLP=liposomal prednisolone phosphate; free PLP $=$ free prednisolone phosphate (see also Tables 1 and 2). 
Table 2

Effects of i.v. administered liposomal PLP and free PLP on anti-angiogenic protein levels in subcutaneous B16.F10 tumor tissue

\begin{tabular}{|c|c|c|c|}
\hline Anti-angiogenic factors & $\begin{array}{l}\text { Reduction induced by liposomal PLP } \\
(\% \text { of reduction as mean } \pm \text { S.D. })\end{array}$ & $\begin{array}{l}\text { Reduction induced by free PLP } \\
\text { ( } \% \text { of reduction as mean } \pm \text { S.D.) }\end{array}$ & $\begin{array}{l}\text { Statistical } \\
\text { differences }\end{array}$ \\
\hline Tissue inhibitor of metalloproteinase 1 (TIMP1) & $2.66 \pm 1.15$ & $1.66 \pm 6.5$ & ns \\
\hline Tissue inhibitor of metalloproteinase 2 (TIMP2) & $31 \pm 10.58$ & $4.66 \pm 8.14$ & $* * *$ \\
\hline Platelet factor 4 (PF4) & $4 \pm 5.29$ & $-1.33 \pm 2.88$ & ns \\
\hline Tumor necrosis factor $\alpha(\mathrm{TNF} \alpha)$ & $17.16 \pm 4.64$ & $-3.8 \pm 3.88$ & $* *$ \\
\hline Interleukin 12 p70 (IL-12 p70) & $14.66 \pm 8.02$ & $9.33 \pm 1.52$ & ns \\
\hline Interleukin 13 (IL-13) & $16.66 \pm 9.71$ & $21 \pm 12.76$ & ns \\
\hline Interferon $\gamma(\mathrm{IFN}-\gamma)$ & $59 \pm 12.28$ & $17.33 \pm 6.11$ & $* * *$ \\
\hline Monokine induced by IFN- $\gamma$ (MIG) & $44 \pm 4.58$ & $48.33 \pm 4.72$ & ns \\
\hline
\end{tabular}

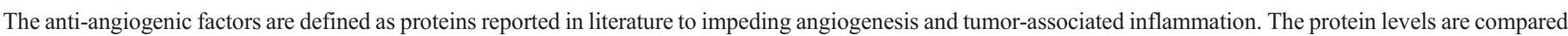

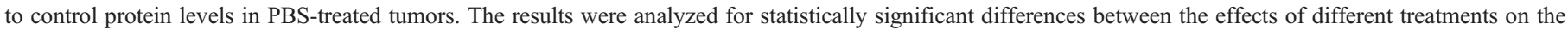

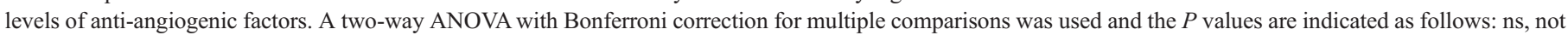
significant $(P>0.05){ }^{*}, P<0.05 ; * *, P<0.01$; and $* * *, P<0.001$. The results represent mean \pm S.D. of three independent experiments.

$(P=0.795)$. The effects of liposomal PLP and free PLP on the intratumoral production of pro-angiogenic proteins are shown in Table 1 and Fig. 3. The levels of the majority of pro-angiogenic factors determined were reduced in case of liposomal and free PLP compared to PBS treatment. Remarkably, for 11 out of 17 pro-angiogenic proteins studied, reduction was stronger and statistically significant after treatment with liposomal PLP than with free PLP. On average, the effect of liposomal PLP on proangiogenic protein levels is $25 \%$ higher than the effect of free plp $(P=0.0191)$. More specifically, liposomal PLP treatment inhibited expression of the pro-angiogenic factors G-CSF, GM-CSF, M-CSF, IL-9 (by 50-75\%) and IL-1 $\alpha$, IL-1 $\beta$, IL-12p40, bFGF (by 75-100\%). Interestingly, expression of one of the most important pro-angiogenic factors, bFGF, was only strongly inhibited (by 78\%) after liposomal PLP treatment, whereas free PLP did not induce any reduction. Also the production of eotaxin in tumors was very strongly inhibited $(75-100 \%)$ by liposomal PLP as well as free PLP treatment. FasL was no longer detectable in tumors treated by liposomal PLP but still detectable in case of free drug treatment. Tumor amounts of IGF-II, TNF- $\alpha$, thrombopoietin, VEGF were not or only slightly influenced by free and liposomal PLP treatment (Table 1). The level of the majority of anti-angiogenic proteins was not or only slightly suppressed by liposomal and free PLP treatment, except for the IFN- $\gamma$ and MIG factors which showed a strong decrease in tumor level after treatment (by 45-60\%). The decrease of IFN- $\gamma$ level was considerably stronger in the case of liposomal PLP treatment (Table 2 and Fig. 3).

\section{Discussion}

The present study provides insight into the mechanism of antitumor action of liposomal PLP [1]. The in vitro and in vivo studies indicate that the underlying mechanism of liposomal PLP responsible for inhibition of tumor growth is based on inhibition of angiogenesis. Inhibition of tumor angiogenesis appears to be due to a strong reduction of intratumoral levels of pro-angiogenic factors as well as to a direct inhibition of endothelial cell proliferation.

To demonstrate in vivo effects of liposomal and free PLP on tumor angiogenesis, we have measured the tumor levels of angiogenic proteins in a subcutaneous B16.F10 melanoma model. The angiogenic protein array monitored both pro- and anti-angiogenic proteins. 17 out of 24 proteins are pro-angiogenic factors. The majority of them (G-CSF, GM-CSF, IGF-II, IL- $1 \alpha$, IL-1 $\beta$, Il-6, IL-9, TNF $\alpha$, MCP1, eotaxin, bFGF, VEGF, leptin, and thrombopoietin) are involved in all tumor angiogenesis steps [13-26]. Most of these factors, such as G-CSF, GM-CSF, MCSF, IL-1 $\alpha$, IL-1 $\beta$, IL-6, IL-9, TNF $\alpha$, MCP1, have proinflammatory effects that strengthen their pro-angiogenic effects and support tumor growth [13,14,16-20,27,28]. Moreover, IL-6 has an anti-apoptotic effect on cancer cells by inhibition of $\mathrm{p} 53$ induced-apoptosis [29]. On the other hand, FasL helps tumor cells to escape immune surveillance by inducing apoptosis of $\mathrm{T}$ cells [30].

The most important effect of liposomal and free PLP on tumor angiogenesis was a strong reduction of most proangiogenic protein levels, whereas the levels of the majority of anti-angiogenic proteins were not affected. As shown in Table 1 and Fig. 3, the reduction of pro-angiogenic protein levels from tumors treated with liposomal PLP was much stronger than that from tumors treated with free PLP. This strong effect is related to the tumor-targeting property of the liposome formulation. The enhanced permeability of blood vessels in solid tumor tissue enables long-circulating liposomes, like those used in this study, to extravasate into the malignant tissue, leading to preferential intratumoral localization of PLP. Once extravasated into the tumor, liposomes appear to accumulate in the surrounding area of capillaries and in macrophages, further increasing effects on two major cell types driving angiogenesis, the endothelial cells and macrophages [31-34]. In contrast, when PLP is administered in free form, it is rapid cleared from the circulation and therefore it is not able to localize in the tumor to a substantial degree, with consequently lower antitumor activity as a result [1]. These findings are supported by our previous observations of intratumoral accumulation of long-circulating liposomes in the immediate vicinity of tumor blood vessels and strong uptake of liposomes by intratumoral macrophages [1]. Reduction of pro-angiogenic factors produced principally by macrophages and endothelial cells may shift the balance between pro- and anti-angiogenic proteins in favor of inhibition of angiogenesis (Fig. 3, Tables 1 and 2). 
Remarkably, expression of bFGF, one of the key proangiogenic factors, was strongly reduced in tumors treated with liposomal PLP, whereas its tumor expression was not affected by free PLP treatment (Table 1 and Fig. 3). bFGF is very important for almost all steps in the angiogenesis process, like degradation of basement membrane, migration of endothelial cells into interstitial space and sprouting and endothelial cell proliferation $[17,26,35]$. A reduction of bFGF level will also inhibit antiapoptotic effects of bFGF on tumor cells $[17,26,29,36]$.

Production of VEGF, the other key pro-angiogenic factor, was not affected by free or liposomal PLP treatment, indicating that not all pro-angiogenic pathways are equally affected. The similar levels of VEGF in tumors treated with free or liposomal PLP as well as control tumors used could be maintained by stimulating factors of VEGF production such as thrombopoietin and TNF- $\alpha$ $[18,19,37-41]$. The levels of these factors were not or only slightly inhibited by free or liposomal PLP treatment (Table 1). Altogether, these results indicate that liposomal PLP treatment does lead to a broad inhibition of pro-angiogenic proteins, but with differential effects on different pathways within the angiogenic process.

In contrast to the pro-angiogenic protein production, the levels of the majority of anti-angiogenic proteins were not affected by liposomal or free PLP treatment (Table 2). The continuing presence of these factors produced mainly by tumor macrophages and $T$ cells strengthens the inhibitory effects resulting from reduction of pro-angiogenic proteins by liposomal and free PLP, through their anti-angiogenic effects (by TNF- $\alpha$, PF4, TIMP 1, TIMP 2, IL-12p70), anti-inflammatory effects (by IL-13) and cytotoxic effects on cancer cells (by TNF- $\alpha$, IL-12p70 and IL-13) $[21,42-47]$. In our study, IFN- $\gamma$ was the only anti-angiogenic factor that was strongly inhibited by liposomal PLP treatment. This may relate to suppressive effects of liposomal PLP on immune cells like $\mathrm{T}$ cells.

The in vitro cytotoxicity studies show that cell viability was only modestly affected for all cell types and both liposomal and free PLP (Fig. 1). Only incubation at the highest concentration of $200 \mu \mathrm{g} / \mathrm{ml}$ over $48 \mathrm{~h}$ induced cytotoxic effects. The in vivo relevance of these observations at extremely high and static drug concentrations for several days is unclear. Average levels of liposomal PLP were $10-20 \mu \mathrm{g} / \mathrm{g}$ tumor tissue at $24 \mathrm{~h}$ after injection of a $20 \mathrm{mg} / \mathrm{kg}$ dose [1]. Intratumoral drug levels induced by liposomal PLP may exceed these values at other time points, but is unlikely to be maintained for days. Therefore, a direct tumor cell killing effect seems to play a relatively minor role, if at all, and certainly does not explain the magnitude of the in vivo antitumor effects of liposomal PLP.

Effects of liposomal PLP on in vitro cell proliferation occurred at lower concentrations, more relevant for the in vivo situation. In the case of HUVEC, the anti-proliferative effect of liposomal PLP was approximately 2- to 3-fold stronger as compared to the two tumor cell types. Interestingly, liposomal PLP inhibited HUVEC proliferation to a 2-fold higher degree than free PLP. This strong effect might be due to a higher intracellular drug concentration induced by liposomal encapsulation possibly as a result of endocytosis of the lipid particles by the endothelial cells.
In conclusion, the screening of proteins known to be involved in the angiogenesis process reveals that the main action of liposomal PLP treatment is inhibition of the production of proangiogenic proteins. The reduction of pro-angiogenic factors shifts the balance between pro- and anti-angiogenic proteins in the tumor to a distinct anti-angiogenic phenotype. In addition, liposomal PLP had a strong inhibitory effect on endothelial cell proliferation in vitro. Although this inhibition was only seen after exposure of HUVEC to high drug concentrations that remained static for prolonged periods of time, the local accumulation of liposomes near tumor capillaries may achieve drug concentrations in this range resulting in direct inhibition of endothelial cell proliferation. Taken together, the present results point to a strong inhibition of tumor angiogenesis as the principal cause for the antitumor activity of liposomal PLP in vivo. One of the future issues is to identify the types of glucocorticoids which show the strongest antitumor activity when they are incorporated in liposomes. Liposomal glucocorticoids could be used in combination with conventional cytostatic agents or antitumor cytokines (IFN, TNF, IL-12p70) to improve cancer treatment. Rapid clinical application may be feasible as both drug and carrier system have been extensively used in the clinic.

\section{Conclusion}

The present study demonstrates that the principal cause of antitumor activity of liposomal glucocorticoids is the strong inhibition of tumor angiogenesis. This beneficial effect is a result of tumor-targeting property of the liposome formulation that increases intratumoral drug concentration and prolongs the inhibitory effects of GC on tumor growth. Consequently, liposomal PLP offers promise for liposomal glucocorticoids as novel antitumor agents.

\section{Acknowledgments}

Manuela Banciu is financed by a Galenos Marie Curie fellowship.

\section{References}

[1] R.M. Schiffelers, J.M. Metselaar, M.H. Fens, A.P. Janssen, G. Molema, G. Storm, Liposome-encapsulated prednisolone phosphate inhibits growth of established tumors in mice, Neoplasia 7 (2) (2005) 118-127.

[2] A. Amsterdam, K. Tajima, R. Sasson, Cell-specific regulation of apoptosis by glucocorticoids: implication to their anti-inflammatory action, Biochem. Pharmacol. 64 (5-6) (2002) 843-850.

[3] S. Schmidt, J. Rainer, C. Ploner, E. Presul, S. Riml, R. Kofler, Glucocorticoid-induced apoptosis and glucocorticoid resistance: molecular mechanisms and clinical relevance, Cell Death Differ. 11 (Suppl 1) (2004) S45-S55.

[4] K.A. Smoak, J.A. Cidlowski, Mechanisms of glucocorticoid receptor signaling during inflammation, Mech. Ageing Dev. 125 (10-11) (2004) 697-706.

[5] F. Buttgereit, R.H. Straub, M. Wehling, G.R. Burmester, Glucocorticoids in the treatment of rheumatic diseases: an update on the mechanisms of action, Arthritis Rheum. 50 (11) (2004) 3408-3417.

[6] F.S. Rouser G., A. Yamamoto, Two dimensional thin layer chromatographic separation of polar lipids and determination of phospholipids by phosphorus analysis of spots, Lipids 5 (1970) 494-496. 
[7] J.M. Metselaar, M.H. Wauben, J.P. Wagenaar-Hilbers, O.C. Boerman, G. Storm, Complete remission of experimental arthritis by joint targeting of glucocorticoids with long-circulating liposomes, Arthritis Rheum. 48 (7) (2003) 2059-2066.

[8] D.A. Scudiero, R.H. Shoemaker, K.D. Paull, A. Monks, S. Tierney, T.H. Nofziger, M.J. Currens, D. Seniff, M.R. Boyd, Evaluation of a soluble tetrazolium/formazan assay for cell growth and drug sensitivity in culture using human and other tumor cell lines, Cancer Res. 48 (17) (1988) 4827-4833.

[9] J. Heil, G. Reifferscheid, Detection of mammalian carcinogens with an immunological DNA synthesis-inhibition test, Carcinogenesis 13 (12) (1992) 2389-2394.

[10] P.L. Huong, A.H. Kolk, T.A. Eggelte, C.P. Verstijnen, H. Gilis, J.T. Hendriks, Measurement of antigen specific lymphocyte proliferation using 5-bromo-deoxyuridine incorporation. An easy and low cost alternative to radioactive thymidine incorporation, J. Immunol. Methods 140 (2) (1991) $243-248$

[11] R.P. Huang, Detection of multiple proteins in an antibody-based protein microarray system, J. Immunol. Methods 255 (1-2) (2001) 1-13.

[12] G.L. Peterson, Determination of total protein, Methods Enzymol. 91 (1983) 95-119.

[13] V.C. Broudy, K. Kaushansky, J.M. Harlan, J.W. Adamson, Interleukin 1 stimulates human endothelial cells to produce granulocyte-macrophage colony-stimulating factor and granulocyte colony-stimulating factor, J. Immunol. 139 (2) (1987) 464-468.

[14] J.R. Jackson, M.P. Seed, C.H. Kircher, D.A. Willoughby, J.D. Winkler, The codependence of angiogenesis and chronic inflammation, FASEB J. 11 (6) (1997) 457-465.

[15] O.H. Lee, S.K. Bae, M.H. Bae, Y.M. Lee, E.J. Moon, H.J. Cha, Y.G. Kwon, K.W. Kim, Identification of angiogenic properties of insulin-like growth factor II in in vitro angiogenesis models, Br. J. Cancer 82 (2) (2000) 385-391.

[16] S. Perdow-Hickman, P. Salgame, Rescue of human T cells by interleukin-9 (IL-9) from IL-2 deprivation-induced apoptosis: correlation with alpha subunit expression of the IL-9 receptor, J. Interferon Cytokine Res. 20 (6) (2000) 603-608.

[17] S. Lutsenko, S.M. Kiselev, S.E. Severin, Molecular mechanisms of tumor angiogenesis, Biochemistry 68 (3) (2003) 349-365.

[18] S.P. Huang, M.S. Wu, C.T. Shun, H.P. Wang, M.T. Lin, M.L. Kuo, J.T. Lin, Interleukin-6 increases vascular endothelial growth factor and angiogenesis in gastric carcinoma, J. Biomed. Sci. 11 (4) (2004) 517-527.

[19] T. Cohen, D. Nahari, L.W. Cerem, G. Neufeld, B.Z. Levi, Interleukin 6 induces the expression of vascular endothelial growth factor, J. Biol. Chem. 271 (2) (1996) 736-741.

[20] F. Bazzoni, B. Beutler, The tumor necrosis factor ligand and receptor families, N. Engl. J. Med. 334 (26) (1996) 1717-1725.

[21] G. Otsuka, T. Nagaya, K. Saito, M. Mizuno, J. Yoshida, H. Seo, Inhibition of nuclear factor-kappaB activation confers sensitivity to tumor necrosis factor-alpha by impairment of cell cycle progression in human glioma cells, Cancer Res. 59 (17) (1999) 4446-4452.

[22] A. Lebrecht, C. Grimm, T. Lantzsch, E. Ludwig, L. Hefler, E. Ulbrich, H. Koelbl, Monocyte chemoattractant protein-1 serum levels in patients with breast cancer, Tumour Biol. 25 (1-2) (2004) 14-17.

[23] M.J. Frederick, G.L. Clayman, Chemokines in cancer, Expert Rev Mol Med 2001 (2001) 1-18.

[24] M.F. Brizzi, E. Battaglia, G. Montrucchio, P. Dentelli, L. Del Sorbo, G. Garbarino, L. Pegoraro, G. Camussi, Thrombopoietin stimulates endothelial cell motility and neoangiogenesis by a platelet-activating factor-dependent mechanism, Circ. Res. 84 (7) (1999) 785-796.

[25] R. Cao, E. Brakenhielm, C. Wahlestedt, J. Thyberg, Y. Cao, Leptin induces vascular permeability and synergistically stimulates angiogenesis with FGF2 and VEGF, Proc. Natl. Acad. Sci. U. S. A. 98 (11) (2001) 6390-6395.

[26] T. Tonini, F. Rossi, P.P. Claudio, Molecular basis of angiogenesis and cancer, Oncogene 22 (42) (2003) 6549-6556.

[27] M.N. Ajuebor, C.M. Hogaboam, T. Le, M.G. Swain, C-C chemokine ligand 2/monocyte chemoattractant protein-1 directly inhibits NKT cell IL4 production and is hepatoprotective in T cell-mediated hepatitis in the mouse, J. Immunol. 170 (10) (2003) 5252-5259.

[28] B. Bottazzi, S. Walter, D. Govoni, F. Colotta, A. Mantovani, Monocyte chemotactic cytokine gene transfer modulates macrophage infiltration, growth, and susceptibility to IL-2 therapy of a murine melanoma, J. Immunol. 148 (4) (1992) 1280-1285.

[29] J. Lotem, L. Sachs, Different mechanisms for suppression of apoptosis by cytokines and calcium mobilizing compounds, Proc. Natl. Acad. Sci. U. S. A. 95 (8) (1998) 4601-4606.

[30] N. Mitsiades, V. Poulaki, G. Mastorakos, S.T. Tseleni-Balafouta, V. Kotoula, D.A. Koutras, M. Tsokos, Fas ligand expression in thyroid carcinomas: a potential mechanism of immune evasion, J. Clin. Endocrinol. Metab. 84 (8) (1999) 2924-2932.

[31] B. Mroczko, M. Szmitkowski, B. Okulczyk, Granulocyte-colony stimulating factor (G-CSF) and macrophage colony stimulating factor (M-CSF) in colorectal cancer patients, Clin. Chem. Lab. Med. 40 (4) (2002) 351-355.

[32] M. Reale, R. Intorno, R. Tenaglia, C. Feliciani, R.C. Barbacane, A. Santoni, P. Conti, Production of MCP-1 and RANTES in bladder cancer patients after bacillus Calmette-Guerin immunotherapy, Cancer Immunol. Immunother. 51 (2) (2002) 91-98.

[33] L. Biancone, A.D. Martino, V. Orlandi, P.G. Conaldi, A. Toniolo, G. Camussi, Development of inflammatory angiogenesis by local stimulation of Fas in vivo, J. Exp. Med. 186 (1) (1997) 147-152.

[34] R. Salcedo, H.A. Young, M.L. Ponce, J.M. Ward, H.K. Kleinman, W.J. Murphy, J.J. Oppenheim, Eotaxin (CCL11) induces in vivo angiogenic responses by human CCR3+ endothelial cells, J. Immunol. 166 (12) (2001) 7571-7578.

[35] M.K. Gupta, R.Y. Qin, Mechanism and its regulation of tumor-induced angiogenesis, World J. Gastroenterol. 9 (6) (2003) 1144-1155.

[36] J.B. Demoulin, J. Van Snick, J.C. Renauld, Interleukin-9 (IL-9) induces cell growth arrest associated with sustained signal transducer and activator of transcription activation in lymphoma cells overexpressing the IL-9 receptor, Cell Growth Differ. 12 (3) (2001) 169-174.

[37] E. Bruno, R.J. Cooper, E.L. Wilson, J.L. Gabrilove, R. Hoffman, Basic fibroblast growth factor promotes the proliferation of human megakaryocyte progenitor cells, Blood 82 (2) (1993) 430-435.

[38] F. Bussolino, A. Albini, G. Camussi, M. Presta, G. Viglietto, M. Ziche, G. Persico, Role of soluble mediators in angiogenesis, Eur. J. Cancer 32A (14) (1996) 2401-2412.

[39] R. Salgado, P.B. Vermeulen, I. Benoy, R. Weytjens, P. Huget, E. Van Marck, L.Y. Dirix, Platelet number and interleukin-6 correlate with VEGF but not with bFGF serum levels of advanced cancer patients, Br. J. Cancer 80 (5-6) (1999) 892-897.

[40] R. Salgado, I. Benoy, R. Weytjens, D. Van Bockstaele, E. Van Marck, P. Huget, M. Hoylaerts, P. Vermeulen, L.Y. Dirix, Arterio-venous gradients of IL-6, plasma and serum VEGF and D-dimers in human cancer, Br. J. Cancer 87 (12) (2002) 1437-1444.

[41] H. Torisu, M. Ono, H. Kiryu, M. Furue, Y. Ohmoto, J. Nakayama, Y. Nishioka, S. Sone, M. Kuwano, Macrophage infiltration correlates with tumor stage and angiogenesis in human malignant melanoma: possible involvement of TNFalpha and IL-1alpha, Int. J. Cancer 85 (2) (2000) 182-188.

[42] I.C. Crocker, M.K. Church, S. Newton, R.G. Townley, Glucocorticoids inhibit proliferation and interleukin-4 and interleukin-5 secretion by aeroallergen-specific T-helper type 2 cell lines, Ann. Allergy, Asthma, \& Immun. 80 (6) (1998) 509-516.

[43] F. Ethuin, C. Delarche, M.A. Gougerot-Pocidalo, B. Eurin, L. Jacob, S. Chollet-Martin, Regulation of interleukin 12 p40 and p70 production by blood and alveolar phagocytes during severe sepsis, Lab. Invest. 83 (9) (2003) 1353-1360.

[44] H.J. Mauceri, S. Seetharam, M.A. Beckett, J.Y. Lee, V.K. Gupta, S. Gately, M.S. Stack, C.K. Brown, K. Swedberg, D.W. Kufe, R.R. Weichselbaum, Tumor production of angiostatin is enhanced after exposure to TNF-alpha, Int. J. Cancer 97 (4) (2002) 410-415.

[45] P. Nyberg, L. Xie, R. Kalluri, Endogenous inhibitors of angiogenesis, Cancer Res. 65 (10) (2005) 3967-3979.

[46] C.Y. Liu, M. Battaglia, S.H. Lee, Q.H. Sun, R.H. Aster, G.P. Visentin, Platelet factor 4 differentially modulates CD4+CD25+ (regulatory) versus CD4+ CD25- (nonregulatory) T cells, J. Immunol. 174 (5) (2005) 2680-2686.

[47] C.R. Yu, R.A. Kirken, M.G. Malabarba, H.A. Young, J.R. Ortaldo, Differential regulation of the Janus kinase-STAT pathway and biologic function of IL-13 in primary human NK and T cells: a comparative study with IL-4, J. Immunol. 161 (1) (1998) 218-227. 